

\title{
Wear behaviour on the radius portion of a die in deep-drawing: Identification, localisation and evolution of the surface damage
}

Christine Boher, D Attaf, Luc Penazzi, Christophe Levaillant

\section{To cite this version:}

Christine Boher, D Attaf, Luc Penazzi, Christophe Levaillant. Wear behaviour on the radius portion of a die in deep-drawing: Identification, localisation and evolution of the surface damage. Wear, 2005, 259 (2, SI), pp.1097-1108. 10.1016/j.wear.2005.02.101 • hal-01717276

\author{
HAL Id: hal-01717276 \\ https://hal.science/hal-01717276
}

Submitted on 7 Nov 2018

HAL is a multi-disciplinary open access archive for the deposit and dissemination of scientific research documents, whether they are published or not. The documents may come from teaching and research institutions in France or abroad, or from public or private research centers.
L'archive ouverte pluridisciplinaire HAL, est destinée au dépôt et à la diffusion de documents scientifiques de niveau recherche, publiés ou non, émanant des établissements d'enseignement et de recherche français ou étrangers, des laboratoires publics ou privés. 


\title{
Wear behaviour on the radius portion of a die in deep-drawing: Identification, localisation and evolution of the surface damage
}

\author{
C. Boher ${ }^{a, *}$, D. Attaf ${ }^{b}$, L. Penazzi ${ }^{a}$, C. Levaillant ${ }^{a}$

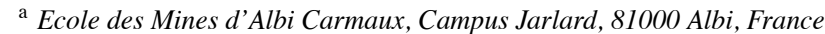 \\ ${ }^{\mathrm{b}}$ Faurecia, Le bois de Flers, 61100 Saint Georges des Groseillers, France
}

\begin{abstract}
The tribology behaviour of the die radius, in the deep-drawing process, results from surface interactions between the metal sheet and the tool under contact pressure. Friction, degradation of the sheet, surface quality and tool wear are a result of this interaction.

This article aims to study degradations of the radius portion of a die in the deep-drawing process. The study on an industrial press is complex, so we developed our own test facility, an experimental device, which represents a deep-drawing process-simulator. It allows friction between the metal sheet and a die radius. It can dissociate the diverse mechanical effects exerted on the die radius by enabling a study of the component conditions found in deep-drawing (effect of the blankholder, of the pulling forces, the sliding rate, etc.).

An experimental study was conducted on a low-carbon steel sheet and a X160CrMoV12 steel die radius. It revealed that the die radius surface was degraded by ploughing and transfer mechanisms. The distribution of these degradations on the die radius was localised in two areas but varied in intensity depending on the exit angle between the sheet and the die radius. The die radius friction coefficient has been modelled with respect to the mechanical characteristics of the deep-drawing process-simulator. This model leads to a correlation between the friction coefficient and the degradation evolutions on the die radius.
\end{abstract}

Keywords: Wear process-simulator; Deep-drawing; Wear mechanisms; Simulation; Friction coefficient

\section{Introduction}

Deep-drawing is the forming process of a blank by plastic deformation. The problems related to deep-drawing can be grouped into three categories [1,2]:

- Problems in maintaining tolerance of the workpiece dimensions.

- Sheet constriction and anisotropy problems. Before rupture, constriction can produce a sheet surface aspect like orange skin, which makes it useless.

- Wear problems. Wear affects both the aspect of the workpiece and, in addition, the die radius is the area of the tool which undergoes the most thermo-mechanical stress.

\footnotetext{
* Corresponding author. Tel.: +33 5634931 69; fax: +33 563493099 . E-mail address: christine.boher@enstimac.fr (C. Boher).
}

The general aim of this work is to focus on the third category by studying the degradation mechanisms of the die radius used in deep-drawing. To do so, a new tribological test has been designed: the wear deep-drawing process-simulator. It is concerned with the die radius wear rather than metal sheet wear.

The bibliography covers various tests for studying friction and wear in relation to the deep-drawing process. Most of these tests study sheet wear rather than tool wear $[3,4]$.

For the plane-drawing test, a strip slides between two plane tools that generate a normal clamping force on it. The objective of this test is to simulate friction conditions operating on the part of the workpiece that is the least deformable but where contact exists over a great sliding length. This test reveals the evolution of asperity deformation.

The Inland test has an identical principle to the above test. The strip slides against a cylindrical tool, and it is plastically 
deformed in this way. Even though this test does not represent real deep-drawing conditions, it enables the study of possible seizure between the strip and the tool.

The Bending test, is more representative of what occurs under a drawing press [3-5]. The friction coefficient can be measured. A strip is plastically curved on a radius cylinder by the application of a traction force. By modifying the pulling forces as well as the restraining forces, the tool radius contact pressure can be changed.

The test called "Restrained Ring" allows the curving of the strip by a ring indentation between two edges up to a specified value $[3,5]$. When this value is reached, the strip slides at a constant speed. The traction and clamping forces are measured. This test is used to investigate the metal strip formability and its roughness through the restrained ring passage.

The Erichsen test of strip expansion on a hemispherical punch is used to study strip formability and ductility under non-axisymmetric expansion conditions [6]. A round punch is pressed on a strip clamped by a blankholder. The metal strip is plastically distorted by expansion with bilateral stretching around the punch bottom making the metal strip thinner. Then the maximum level before sheet tearing is recorded using predefined conditions of punch speed and blankholder clamping force.

Finally, The Swift test is a deep-drawing test using a flat bottom punch that has been codified by the International Deep-Drawing Research Group (IDDRG) [2]. Mechanical analyses of this test allow a correlation of the friction coefficients of the blankholder and the tool radius using pre-defined conditions of pressure and speed. The reach limiting drawing ratio can be obtained with this test.

In the current study, a new tribological test to study friction and wear of a die radius in the deep-drawing process was used. We focused our study on the degradation of the die radius; the strip surface degradation is not investigated. After the presentation of the deep-drawing process-simulator, the results will demonstrate that there are always two mechanisms of degradation on the die radius. These two mechanisms are not localised in the same areas on the die radius and they have a different evolution according to the cycle number.

\section{Experimental friction equipment: the deep-drawing process-simulator (DDPS)}

The aim of the deep-drawing process-simulator is to study the tribological interaction between the metal strip and the tool (Fig. 1). The strip slides over the die radius to simulate drawing conditions. With this process-simulator, laboratory tests were performed under quasi-industrial conditions (materials, loading, evolution over time, sliding velocity, lubrication, etc.).

A steel strip, unrolled directly from a coil, was in contact with a portion of the radius tool. The flat blankholder and the die radius constituted the working system of our DDPS. A rolling up engine pulled the strip through this working system (Fig. 2). The loading of the die radius was a result of the restraining forces $(H)$ and the pulling forces $(T)$. The blankholder forces were controlled by a hydraulic cylinder.

The sliding of the steel strip over the die radius varied in accordance with a defined angle $(\alpha)$ which simulates the running of the strip steel on the tool (Figs. 3 and 4). We fixed the strip exit angle $(\alpha)$ in relation to the angular position of the reversing cylinder.

With the rolling up and unrolling engines and with a programmable logic control unit, two user modes can be programmed: either continuous or repeated sliding of the strip over the tool. In the continuous case, the mechanical load-

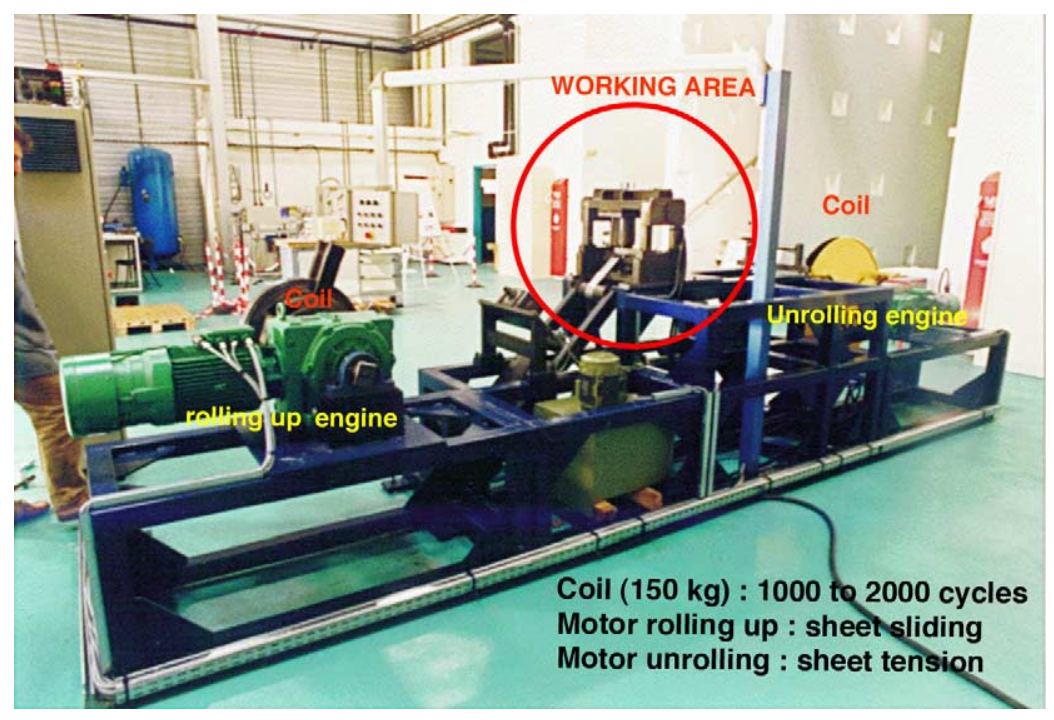

Fig. 1. Global view of the deep-drawing process-simulator. 


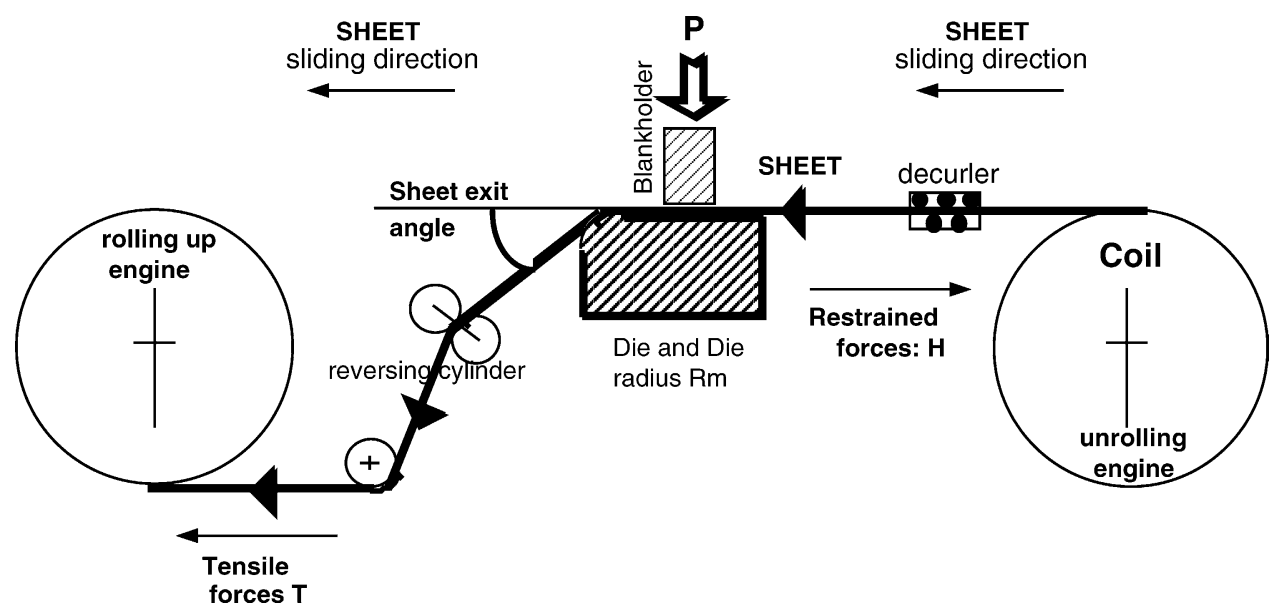

Fig. 2. Diagram of the DDPS.

ing conditions are constants, so the closed friction contact is not refreshed by air convection the contact temperature increases and produces thermal friction. In the repeated sliding cycle, we load and unload the contact, and thus refreshing contact conditions are produced. However, the effects

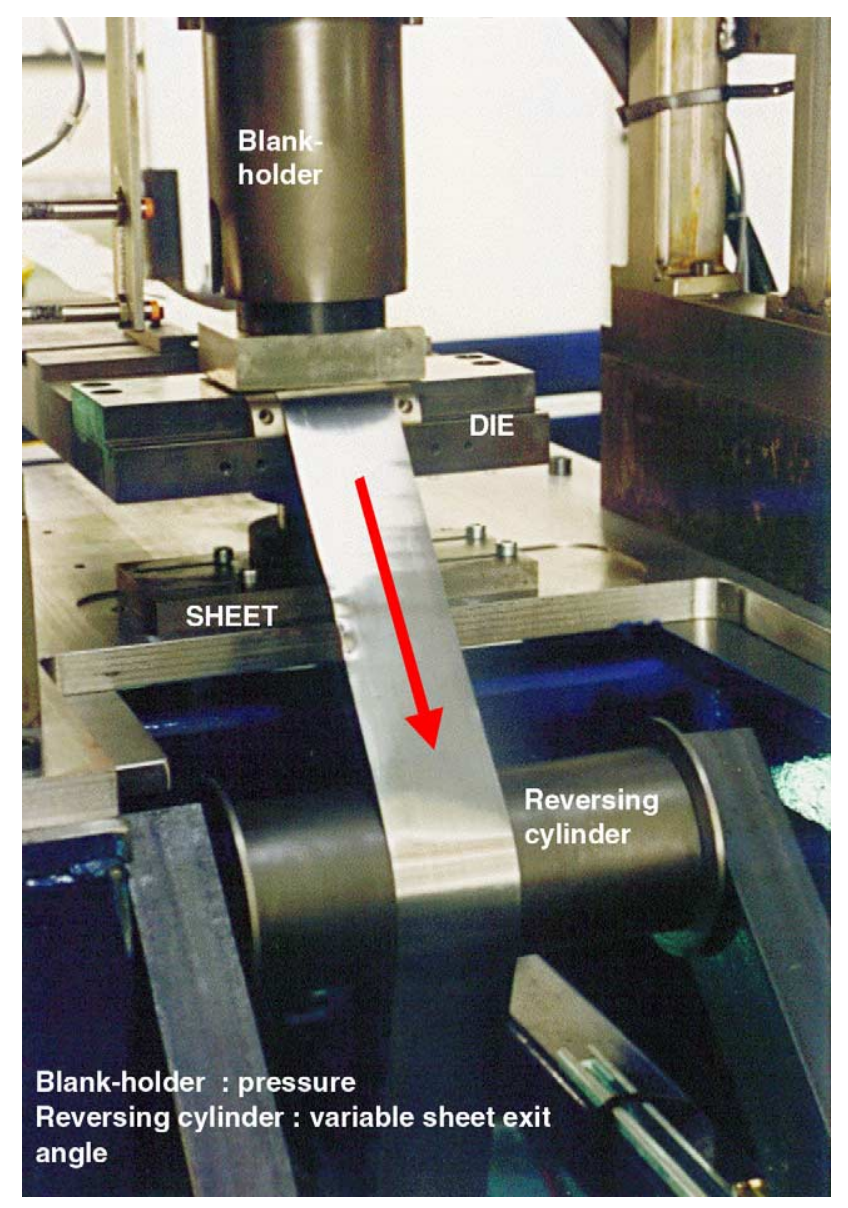

Fig. 3. Magnification of the active part of the process simulator: visualisation of the samples. of loading and unloading produce mechanical fatigue of the die radius.

\section{Materials and samples}

The die radius steel grade is X160CrMoV12 (AISI D2 or DIN 1.2379). The chemical composition (in wt.\%) is given in Table 1. Steel AISI D2 is commonly used in the deep-drawing process. It contains $12 \%$ chromium with a large quantity of free carbides, which confer great wear resistance (Fig. 5). The steel is quenched at $1080^{\circ} \mathrm{C}$ for $30 \mathrm{~min}$ and tempered twice for $1 \mathrm{~h}$ at $200{ }^{\circ} \mathrm{C}$ to a hardness of $60 \mathrm{HRC}$. The die radius is $R_{\mathrm{m}}=6 \mathrm{~mm}$ (Fig. 6). The arithmetic roughness ( $\left.\mathrm{Ra}\right)$ of the die radius is $1.02 \mu \mathrm{m}$.

The strip is made of low skin-passed steel used in cold forming, DC04 grade steel (DIN 1.0338) (Table 1). The strip is covered with a thin, protective oil film. The metal strip is $50 \mathrm{~mm}$ wide, $1 \mathrm{~mm}$ thick and the coil length is $150 \mathrm{~m}$. The strip mechanical characteristics are detailed in Table 2. These values will be required to calculate the friction coefficient between the die radius and the sheet.

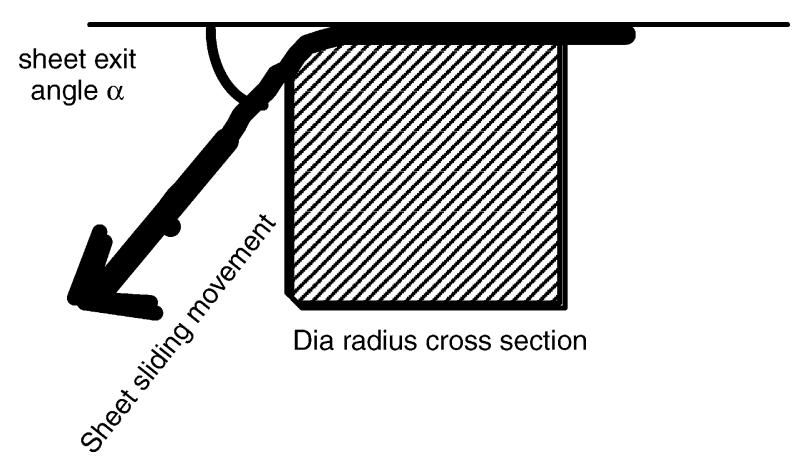

Fig. 4. Diagram of the active part of the process simulator: visualisation of the strip exit angle $(\alpha)$. 


\begin{tabular}{llllllllll}
\hline & $\mathrm{C}$ & $\mathrm{Cr}$ & $\mathrm{Mo}$ & $\mathrm{Mn}$ & $\mathrm{V}$ & $\mathrm{Si}$ & $\mathrm{S}$ \\
\hline DIN 1.2379 & $1.45-1.6$ & $11-13$ & $0.7-1$ & $0.2-0.6$ & $0.7-1$ & $0.1-0.6$ & 0.03 \\
DIN 1.0338 & 0.08 & - & - & 0.4 & - & - & 0.03 & 0.03 & 0.03 \\
\hline
\end{tabular}

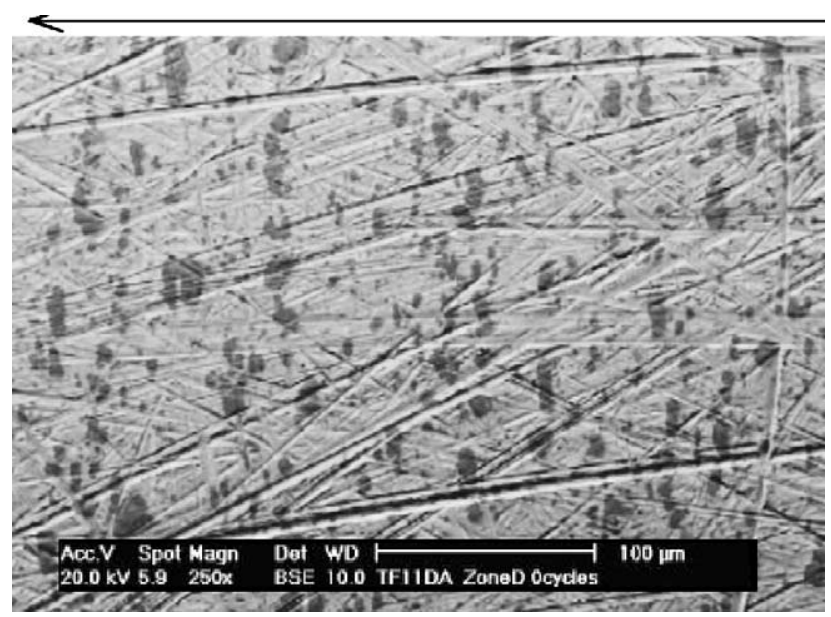

Fig. 5. Die radius without degradation: visualisation of carbides in dark zones (SEM observations with back scattering electrons).
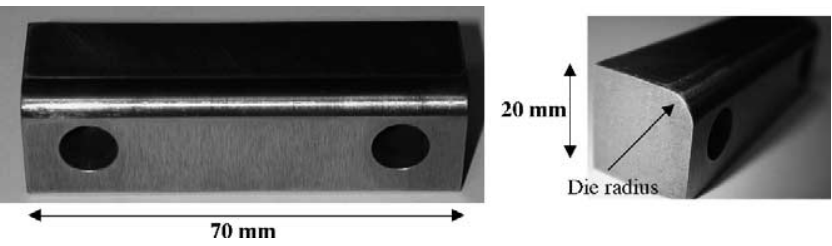

Fig. 6. X160CrMoV12 (AISI D2 or DIN 1.2379) die sample of the DDPS.

\section{Tests on the wear deep-drawing process-simulator}

\subsection{Introduction}

In the real deep-drawing process, the punch displacement involves a strip exit angle $(\alpha)$ scanning the die radius from $0^{\circ}$
Table 2

Strip mechanical characteristics

\begin{tabular}{lc}
\hline Hardening coefficient, $n$ & 0.225 \\
Consistancy, $K(\mathrm{MPa})$ & 530 \\
Poisson coefficient, $v$ & 0.3 \\
Young modulus, $E(\mathrm{GPa})$ & 210 \\
Shear modulus, $G(\mathrm{GPa})$ & 80 \\
Hardness $(\mathrm{MPa})$ & 320 \\
Thickness, $e(\mathrm{~mm})$ & 1 \\
Width, $l(\mathrm{~mm})$ & 50 \\
\hline
\end{tabular}

to $90^{\circ}$. In our process-simulator, varying the strip exit angle $(\alpha)$ allows us to understand at which angle $(\alpha)$ position, the die radius is the most worn by the strip sliding.

To evaluate the influence of this exit angle $(\alpha)$ on the repartition and amplitude of the die radius contact pressure, a finite element model was designed (Fig. 7). This model reproduces the geometry of the die radius and the test conditions of the DDPS $[7,8]$. The pressure distribution is variable with two zones of strong pressures: one at the entry of the die radius and the other at the exit of the contact between the strip and the die radius. There is, therefore, a variation in the localisation and the amplitude of the two high-pressure peaks according to the strip exit angle $(\alpha)$. In this paper, the strip exit angles studied $(\alpha)$ are $70^{\circ}, 80^{\circ}$ and $90^{\circ}$. Our experimental results were divided into three parts.

1. Identification of mechanisms of the die radius degradation.

2. Location of these surface degradations on the die radius.

3. Evolution of these surface degradations on the die radius in function of the cycle number.

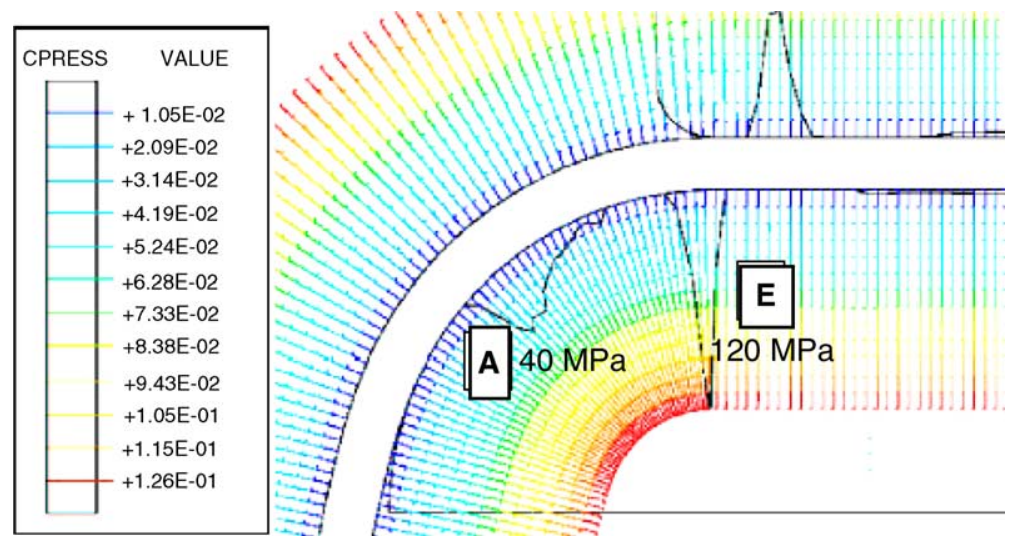

Fig. 7. Numerical model of our DDPS: meshing of the die radius and observations of the two pressure peaks at the entry of the contact (E) and at its exit (A). 

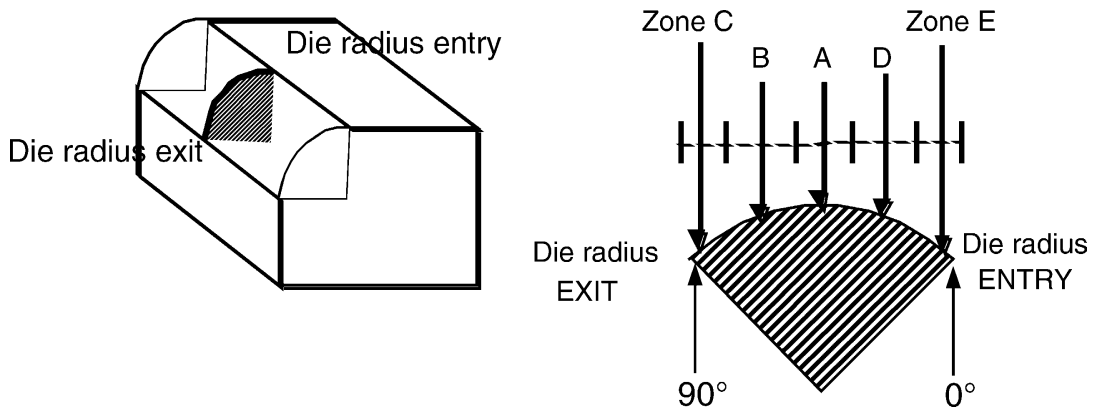

Fig. 8. Schema of the die radius and localisation - on the central part - of the micrographs for SEM observations.

Table 3

Test parameters with the DDPS

\begin{tabular}{ll}
\hline Sliding speed, $V(\mathrm{~mm} / \mathrm{s})$ & 50 \\
Sliding distance, $L(\mathrm{~mm})$ & 100 \\
Blankholder pressure, $P(\mathrm{MPa})$ & 4 \\
Strip exit angle, $\alpha\left(^{\circ}\right)$ & 70,80 and 90
\end{tabular}

\subsection{Test parameters}

The parameters (sliding speed, blankholder pressure, sliding distance, etc.) are selected to obtain a degradation of the die radius after only 1200 cycles (one coil). The selected parameters are given in Table 3:

\subsection{Observation techniques for wear on the die radius}

Tools were observed by scanning electron microscope (SEM) at each 100 cycles to track die radius surface damage. Only the die radius central section was observed which was then divided into five sub-sections (Fig. 8). The chemical elements of the die radius surface were analysed by electron dispersive spectroscopy. This analysis demonstrated that the only perceptible difference in the tool and sheet iron grades is the relative value of chromium content. The metal strip has no chromium content. For this reason, the weight percent of chromium evolution will be a solution to reinforce our findings concerning the degradation behaviour of the surface.

\section{Results}

\subsection{Identification of degradation mechanisms on the die radius}

Two mechanisms of surface degradation were identified on the die radius through the micrographs: adhesion and ploughing. Adhesion was in evidence from transferred particles and ploughing by the formation of grooves by plastic deformation.

The strip transfer on the die radius consisted of very small particles about $10 \mu \mathrm{m}$ diameter (Fig. 9). Transferred particles were identified by energy dispersive spectroscopy analysis. With the same analysis conditions and the same specific volume of interaction, the chromium content decreased (4\% instead of $12.7 \mathrm{wt} . \%$ ) when a transferred particle of the strip material was identified (Fig. 10).

The strip particles are essentially embedded in the tool grinding grooves (Fig. 11). Transfer is essentially due to mechanical interlocking of strip asperities on the die roughness. Some researchers have noticed that transfer is initiated with small particles "lumps" that grow by propagation to form lamellar structures $[9,10]$.

The formation of grooves (or ploughing) results in fine scratches on the die radius (Fig. 12). The carbides, $\mathrm{M}_{7} \mathrm{C}_{3}$, contained in tool steel, play an important role in the formation of these scratches. The die radius matrix plastically flows around these carbides. Like the particle transfer mechanism, the ploughing damage rises as the strip exit angle $(\alpha)$ increases.

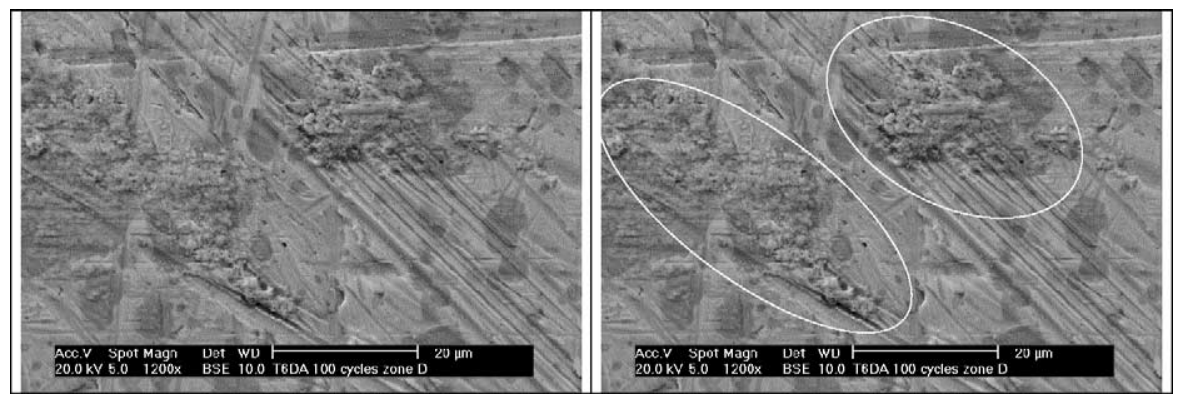

Fig. 9. Example of die radius wear by transfer particles after 100 cycles (on the left the real micrograph, on the right in red lines, the transferred particles). 


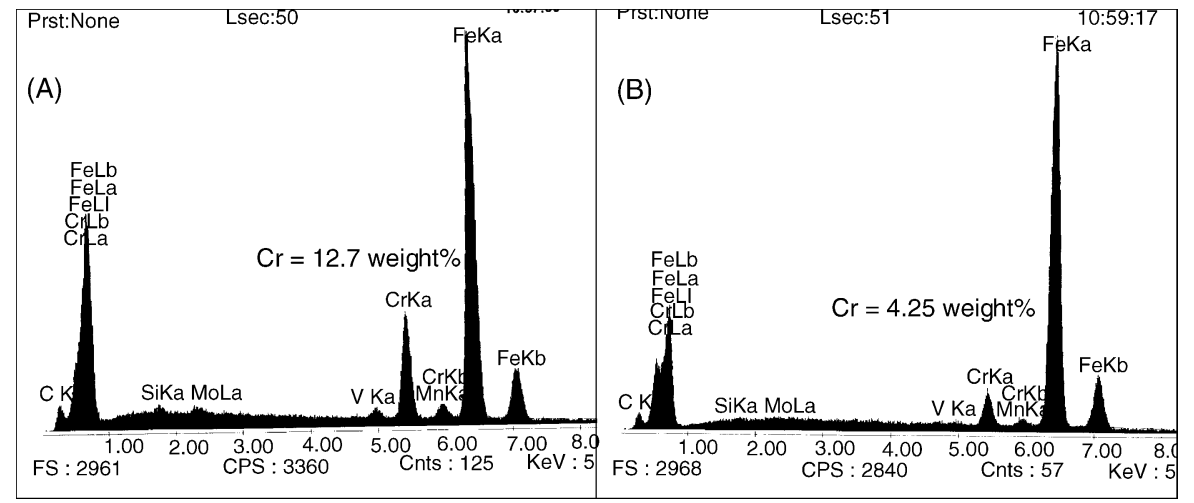

Fig. 10. Energy dispersive spectroscopy analysis of die radius: (a) before wear and (b) analyses of a transfer zone: diminution of the chromium content.

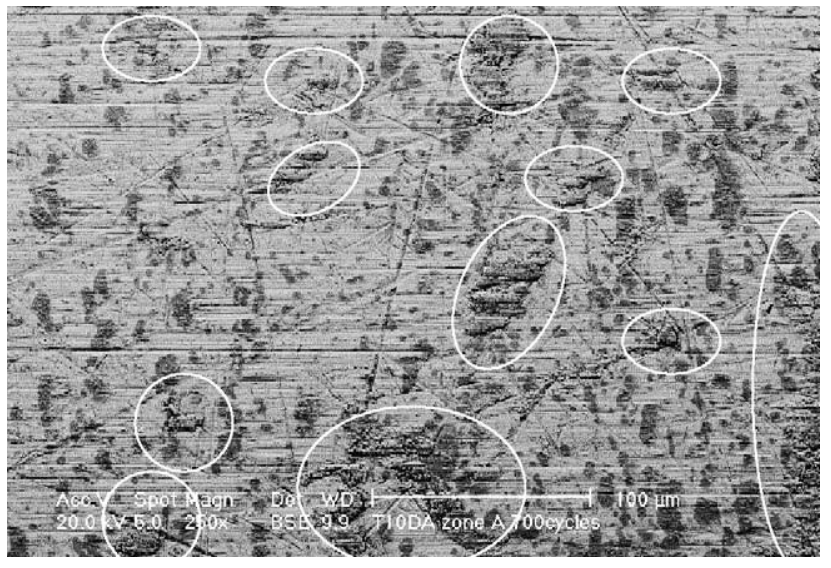

Fig. 11. Transferred particles embedded in the die grinding grooves. Example of die radius wear (transfer) after 700 cycles $\left(\alpha=90^{\circ}\right)$ in zone A (in white lines, the transferred particles).

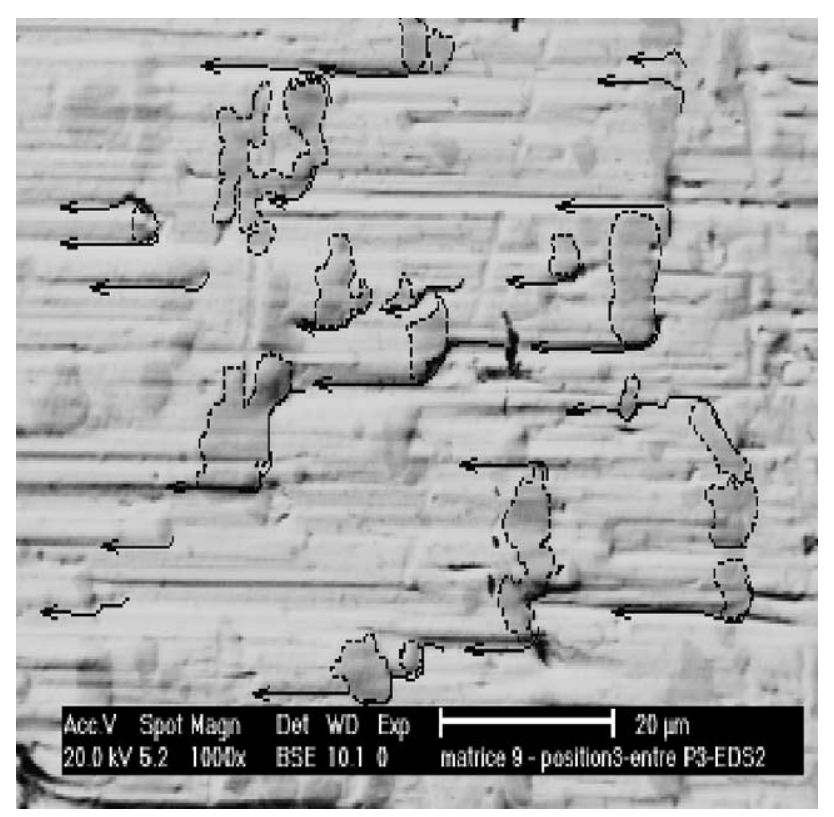

Fig. 12. Visualisation of the ploughing mechanism on the die radius. The plastic flow occurs around the carbides $\left(\right.$ angle $=90^{\circ}$ ).

\subsection{Location of degradations on the die radius}

The observations with the scanning electron microscope highlight two zones of the die radius where degradations are present.

In order to make very precise die radius surface observations, with the motorised SEM stage, the die radii have been scanned each $350 \mu \mathrm{m}$ for a circumference from $0^{\circ}$ to $90^{\circ}$. These investigations revealed that the transfer is localised in two definite zones: the entry of die radius (zone E) and a zone located between $40^{\circ}$ and $50^{\circ}$ according to the strip exit angle $(\alpha)$ (zone A). The plastic deformations induced by the ploughing mechanism are only observed at the entry of the die radius (zone $\mathrm{E}$ ).

The equivalence between the damage observations observed by SEM stage and the die radius angle $(\beta)$ is given in Fig. 13 and in Table 4.

The location of the first damage zone on the die radius is the same for the strip exit angles $70^{\circ}$ and $80^{\circ}$ but is quite different for $90^{\circ}$. For the second zone, the damage locations are quite similar.

The contact between the strip and the die is not the same in function of the exit angle. It is more difficult to curve

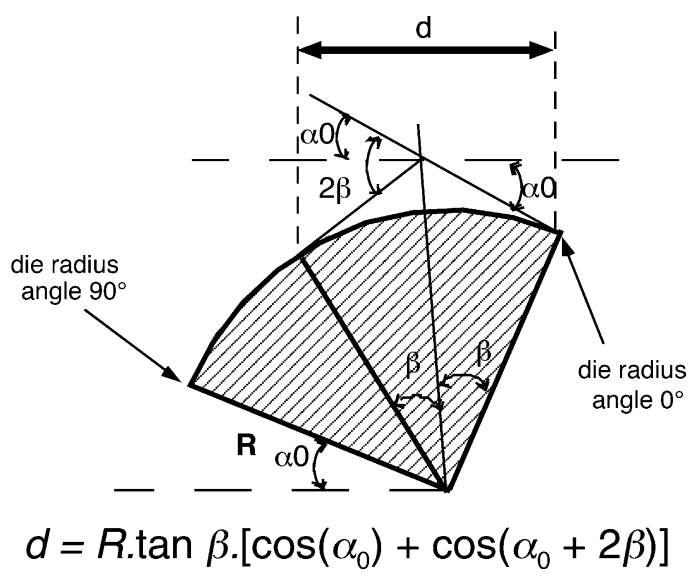

Fig. 13. Diagram of the equivalence between the damage observations localised by SEM stage and the die radius angle $(\beta)$. 
Table 4

Correspondence between SEM observations on the die radius and die radius angle $(\beta)$

\begin{tabular}{|c|c|c|c|c|c|c|}
\hline \multirow{2}{*}{$\begin{array}{l}\text { Strip exit anglem, } \\
\alpha\left(\left(^{\circ}\right)\right.\end{array}$} & \multicolumn{3}{|c|}{ First zone transfer + ploughing mechanisms } & \multicolumn{3}{|c|}{ Second zone transfer mechanism } \\
\hline & Area width, $d(\mu \mathrm{m})^{\mathrm{a}}$ & Area width $\left(2 \beta^{\circ}\right)$ & Median position $\left(2 \beta^{\circ}\right)$ & Area width, $d(\mu \mathrm{m})^{\mathrm{a}}$ & Area width $\left(2 \beta^{\circ}\right)$ & $\begin{array}{l}\text { Median position } \\
\left(2 \beta^{\circ}\right)\end{array}$ \\
\hline 80 & $150-450$ & $2.0-5.8$ & 3.9 & $4100-5000$ & $43.6-52.2$ & 47.8 \\
\hline 90 & $720-1030$ & $9.1-12.6$ & 10.8 & $4460-4850$ & $47.1-50.8$ & 48.9 \\
\hline
\end{tabular}

a Area width $(d)$ : the degradation area width is calculated from the distance " $d$ " obtained from the origin of the die radius.

the strip with an exit angle of $90^{\circ}$. The strip thickness and its mechanical properties play a role in the strip bending stiffness and the contact zones are different from the others angles.

To understand the areas of the degradations observed, the results of our numerical simulation (Fig. 7) were used. The numerical simulation model has shown that the pressure distribution is not constant on the die radius and it varies according to the test parameters (blankholder pressure, strip exit angle $(\alpha)$, die radius, etc.), the strip properties and design as well as the friction coefficient $[5,6,11,12]$. One previous study pointed out that the areas of high pressures obtained by numerical simulation are the same as the areas of the degradations obtained from the wear process simulator tests $[7,8]$. Correlation between surface damage of the die radius and the pressure level can be made.

\subsection{Evolution of the wear damage in function of the cycle number}

Microscopic observations of the die radius surface are made at different cycle number $(100,300,500,700,900$ and 1200 cycles). For a strip exit angle $(\alpha)$ of $70^{\circ}$, the degradation of the die radius occurs preferentially by the adhesion mechanism. Strip particle transfer is located in zones E and A on the die radius and starts from 100 cycles. For this cycle number, the ploughing scratches in zone E are not observed. Between 100 and 700 cycles, there is no significant evolution. From 700 cycles, in zone A, larger transferred particles are present on the die radius surface (Fig. 14) and some scratches begins to appear. These scratches affect the transferred particles surface but not really the die surface.
The degradation evolution for a strip exit angle $(\alpha)$ of $80^{\circ}$, looks like the $70^{\circ}$ angle one. The die radius is little marked by the ploughing mechanism and the transfer is visible in zone A.

For the $90^{\circ}$ angle, the adhesion mechanism, in zone A, is observed from 100 cycles (Fig. 15) and some scratches of ploughing are also observed in zone E (Fig. 16). These scratches affect the die surface and not only the transferred particles like previously. From 700 cycles, there is a real increase of the wear damage in zone E (entry of the contact). The waves of plastic deformation are significant and they go round the carbides (Fig. 17). In zone A (exit of the contact), surface damage is always due to transferred particles (Fig. 18).

\subsection{Friction coefficient results}

The friction coefficient $\left(f_{\mathrm{m}}\right)$ between the strip and the die radius is calculated according to a model given in Eq. (1) [7]. This model is based on the bibliography $[13,14]$ and the mechanical analysis of our DDPS (Fig. 2) (Appendix A).

$f_{\mathrm{m}}=\frac{R_{\mathrm{m}}+e / 2}{\theta R_{\mathrm{m}}} \ln \left(\frac{T^{\prime}-F_{\mathrm{u}}}{H+F_{\mathrm{b}}}\right)$

where $R_{\mathrm{m}}$ is radius of the die, $e$ the strip thickness, $T^{\prime}$ the tensile force applied on the die radius, $H$ the restrained force and $\theta$ is the contact angle between the strip and the die radius. $F_{\mathrm{u}}$ and $F_{\mathrm{b}}$ are the unbending and bending forces acting on the strip.

The different parameters necessary to calculate the friction coefficient were obtained from the variations in the rolling up engine electrical currents (Appendix A). We established
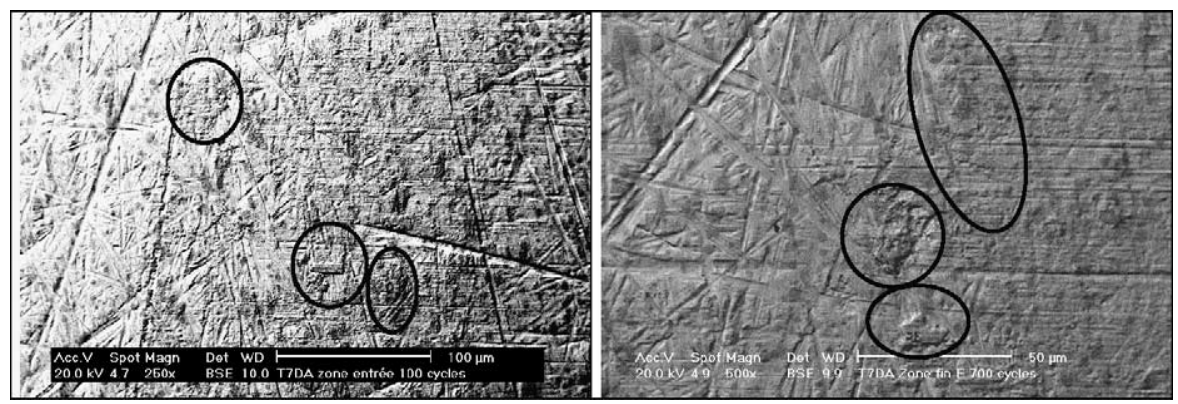

Fig. 14. Die radius degradation for $\alpha=70^{\circ}$ in zone E after 100 cycles on the left and after 700 cycles on the right (in black lines, the transferred particles). 


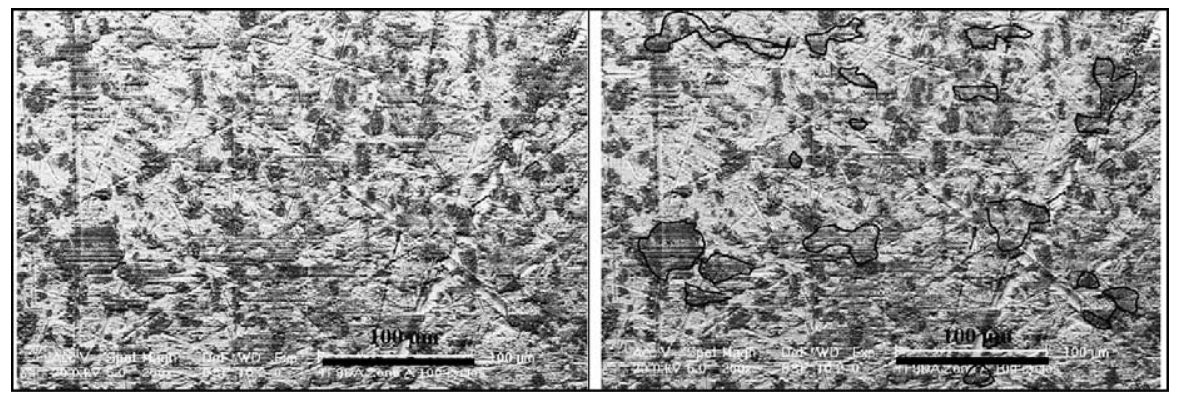

Fig. 15. Die radius degradation for $\alpha=90^{\circ}$, at the exit of the contact (zone A) after 100 cycles (on the left the real micrograph, on the right, in black lines, the transferred particles).

a measurement routine of these parameters according to various test configurations. This routine requires test interruptions. Stopping every 100 cycles, we measured the different value of engine electrical currents for each of 10 cycles. This was necessary to calculate friction - under three test conditions: (1) with a strip exit angle $(\alpha)$ of $0^{\circ}$ and without load (blankholder); (2) with a strip exit angle $(\alpha)$ of $0^{\circ}$ and under load and (3) finally under the test conditions.

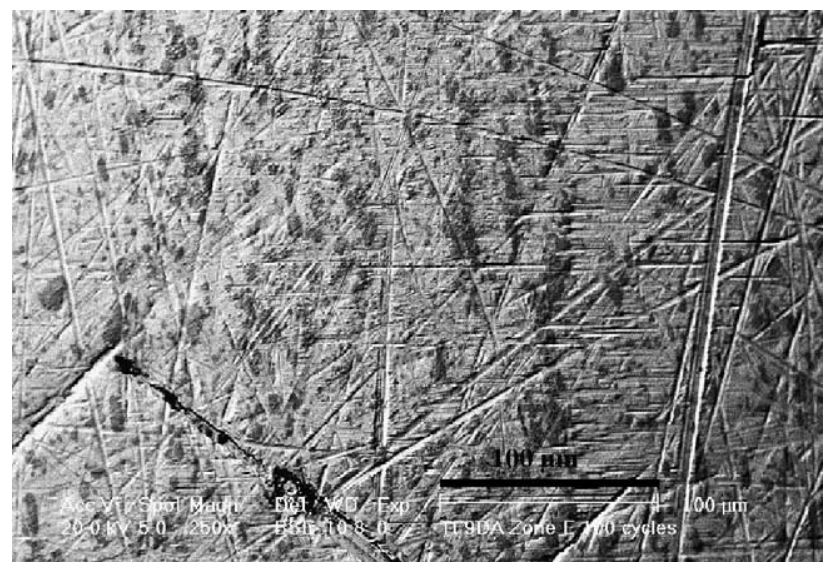

Fig. 16. Die radius degradation for $\alpha=90^{\circ}$, at the entry of the contact (zone E) after 100 cycles.

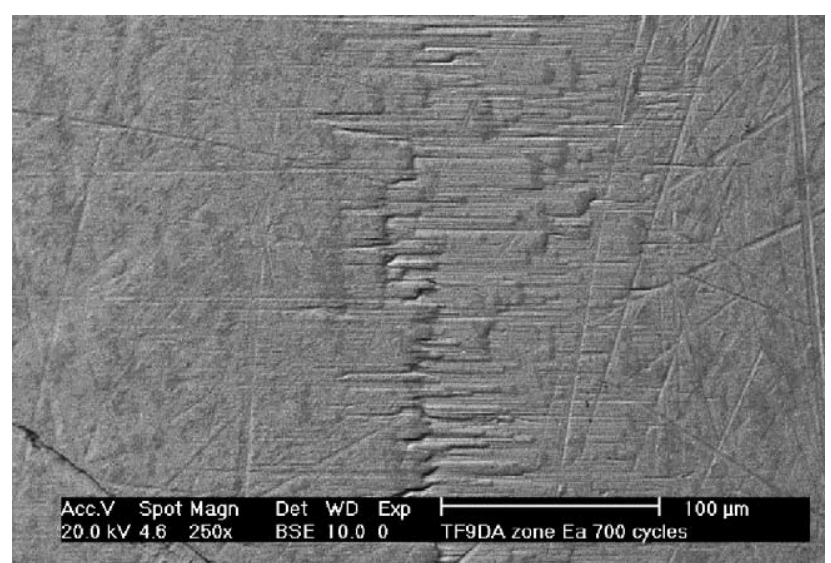

Fig. 17. Die radius degradation for $\alpha=90^{\circ}$, at the entry of the contact (zone E) after 700 cycles: ploughing wear mechanism.
For each strip exit angle $(\alpha)$, three tests of 1200 cycles were carried out with many interruptions to measure the friction coefficient (Fig. 19). To compare the friction curves obtained for the three strip exit angles $(\alpha)$, we calculate polynomial curves from the average tendency for a given exit angle. The friction coefficient evolution results are presented in Fig. 20.

We notice a great similarity for the three angles, especially for the strip exit angle $(\alpha)$ of $70^{\circ}$ and $80^{\circ}$. For these two angles, the values of friction coefficient vary from 0.65 to 0.5 at the end of the test. For the angle $90^{\circ}$, the values are weaker and limited to 0.5 and 0.4 .

The evolution of the friction coefficient presents three fields. The friction coefficient is high and quite constant in the first field. It decreases in the second one and in the last field, it is low and quite constant. The fields I and II correspond to the running-in period of the test for the three angles and the stabilisation of the friction coefficient is observed after 600 cycles. The friction coefficient evolution could be correlated with the evolution of the wear damage. The initial lower values obtained for a strip exit angle of $90^{\circ}$ indicate that the abrasion mechanism is more significant. In opposite, the high value for $70^{\circ}$ and $80^{\circ}$ could indicate that the adhesion mechanism is more important. After 600 cycles for all the angles, abrasion mechanism at the entry of the contact is observed and there is no evolution of the wear damage at the surface die radius.

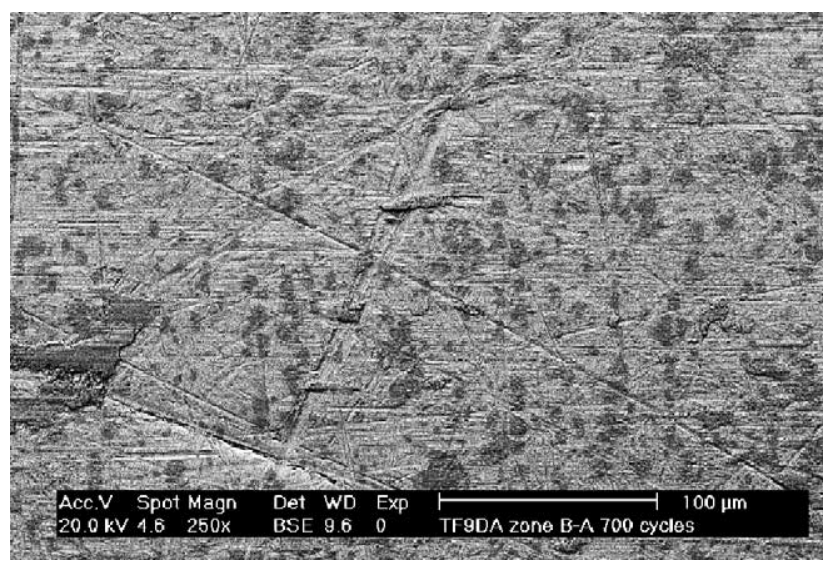

Fig. 18. Die radius degradation for $\alpha=90^{\circ}$, at the exit of the contact (zone A) after 700 cycles: transferred particles. 
Friction coefficient

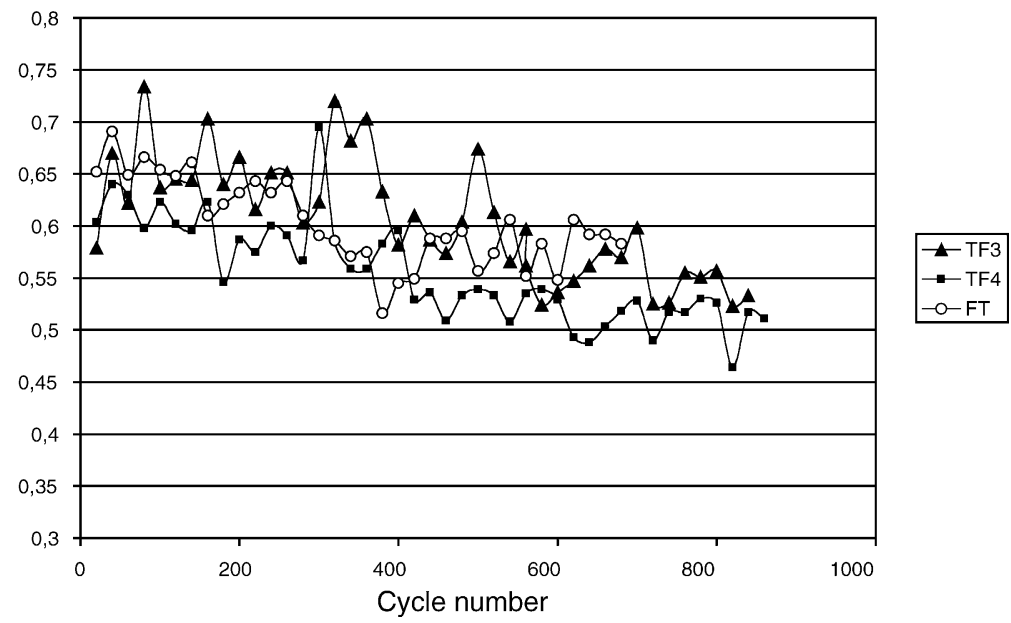

Fig. 19. Example of the friction coefficient evolution in function of the cycle number for the strip exit angle $(\alpha) 70^{\circ}$.

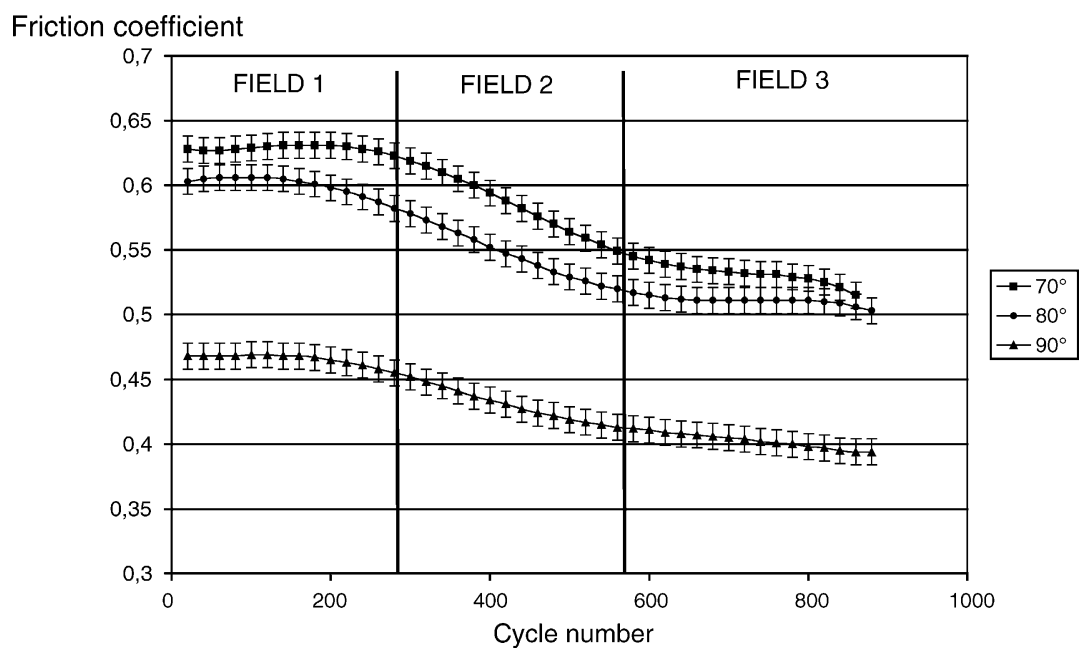

Fig. 20. Friction coefficient evolution in function of the cycle number for the three strip exit angles $(\alpha)$.

\section{Discussion}

Wear surface damages are localised in two specific zones on the die radius and these locations are confirmed by a finite element model which gives mechanical response of a deep-drawing die radius. More specifically, there is a good agreement between high-pressure contact areas (FE model) and localised transfer zones (experiments). Two mechanisms of surface degradation are identified on the die radius through adhesion (or adherence) and ploughing. Adhesion is identified by transferred particles and ploughing by the formation of grooves by plastic deformation. Adherence could be also used because the strip asperities (named particles with global observations) are essentially embedded in the tool grinding grooves.

The transfer and ploughing mechanisms are thus correlated with the pressure distribution on the die radius. The model argue that the transfer mechanism can occur for val- ues of pressure weaker than those necessary to generate the ploughing mechanism.

When the ploughing mechanism is present, it occurs only on the entry of the contact (zone E), where the pressures are higher, whereas the transfer mechanism exists in zones A and $\mathrm{E}$.

In these test conditions, the initial lubrication of the sheet is not sufficient to avoid asperity contact with the die and the die radius friction is carried out under boundary or mixed lubrication.

For a strip exit angle of $70^{\circ}$ and $80^{\circ}$, the main wear damage at the surface of the die radius is adhesion or adherence. The transferred particles are observed at the entry of the contact (zone E) but also at the exit of the contact in zone A. The quantity of the transferred particles increases essentially in this last zone with the cycle number. For these angles, the abrasion mechanism is not really observed. For a strip exit angle of $90^{\circ}$ the main wear damage at the surface of the die 
radius is ploughing. This degradation is located at the entry of the contact and it increases in function of the cycle number.

The friction coefficient of the die radius is calculated with a specific model using the mechanical characteristics of the DDPS and the mechanical properties of the strip. The calculated coefficient is a global friction coefficient on the die radius. It integrates all the contact phenomena occurring on all the zones of contact of the die radius. The correlation of the wear surface evolution with the friction coefficient evolution could explain the three fields of the friction coefficient. In field I the strip transfer mechanism or adhesion mechanism on the die radius is dominating. The ploughing mechanism is then dominating starting from field III. Field No. II corresponds to the progressive transition of the two mechanisms. The high values of the friction coefficient are associated with adhesion and the lower value with ploughing. The ploughing mechanism is more important for a strip exit angle $(\alpha)$ of $90^{\circ}$. In this case, the friction coefficient is less high than the $70^{\circ}$ and $80^{\circ}$ one. For the strip exit angle $(\alpha)$ of $90^{\circ}$, the die radius contact pressure seems to be more important.

The ploughing mechanism could be induced by a mechanical fatigue phenomena, because it is not well observed at the beginning of cycles like transfer phenomena. Degradation evolution reveals that the transfer mechanism occurs after the first cycles whereas the mechanism of ploughing is visualised after 500 or 700 cycles, under our conditions.

To understand the transfer mechanism it is necessary to consider the mechanical behaviour of the strip asperity. For an elastic deformation of the asperity, the contact model is based on Hertz theory. With transferred particles, the deformation mode is based on plastic or visco-plastic behaviour of the strip asperity. Sliding could induce large deformations in one of the two antagonists. The plastic deformation thickness may reach a few micrometers in function of tribological conditions. These tribological transformations corroborate that the material has got a ductile behaviour [15-18]. Others authors confirm the assumption of ductile deformation with the mechanism of transfer and adhesion $[10,19]$.

In our present study, to explain the transfer particles, we consider three steps in the asperity behaviour. For instance the thermo-mechanical aspect is not yet study - the transfer assumptions are only based on a mechanical theory.

The contact leads to plastic deformation conditions.

The strip asperities, sliding on the die radius, have got a ductile behaviour.

The notion of a low cycle fracture model is of prime necessity to understand the particle transfer.

Under contact pressure and shearing stresses they plastically flow with ductile behaviour. Under high-contact pressure, low cycle number is necessary to break of the asperity and the opposite for low contact pressure. Theses assumptions could explain the difference of transferred particles evolution between the entry and the exit of the contact on the die radius.

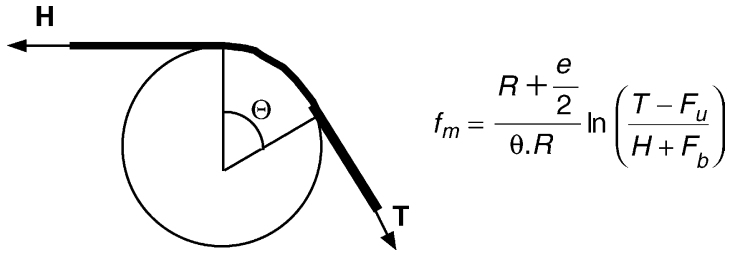

Fig. A.1. Diagram to model the friction coefficient on a radius portion.

\section{Conclusion}

The deep-drawing process-simulator, designed in our laboratory is interesting because it is possible to simulate quasiindustrial conditions and to study the influence of the strip exit angle on the die radius degradation. It also allows a great length of strip to study the wear behaviour of the die surface. For most of the tribological tests used in the deep-drawing field, the strip sliding length is rather short and the wear behaviour is studied on a few cycles. The die radius surface observations confirm that wear industrial phenomena can be reproduced on the process simulator: strip particle transfer is the main wear damage and it is located on two specific areas of the die radius. Ploughing or abrasion is essentially observed at the entry of the die radius. There is a good agreement between high-pressure contact areas calculated by a finite element model and localised wear zones. The tribological behaviour of the die radius is quite different in function of the strip exit angle. For low strip exit angles, particle transfer on the die radius is important and for high strip exit angle, the main damage is abrasion. The friction coefficient may also give informations about the contact evolution. Its modelling depends on the specificities of the DDPS. This wear processsimulator can be used to study different grades of die radius or strip.

\section{Appendix A. Measurement of the friction coefficient of a die radius portion on our wear DDPS}

The calculation of the die radius friction coefficient, on our DDPS, is based on an analytical theory obtained with the bibliography for the expression of a strip friction coefficient on a cylinder. The second part of this calculation is based the engine outputs and required to interpret the strip traction on this equipment.

\section{A.1. General model of the strip friction coefficient on a cylinder}

Authors $[13,14]$ have established a relation for the friction coefficient $\left(f_{\mathrm{m}}\right)$ of a strip on a cylinder - with a radius $(R)-$ in function of the tensile force $(T)$ and the restrained force $(H)$ (Fig. A.1 and Eq. (1)). $F_{\mathrm{u}}$ and $F_{\mathrm{b}}$ are the unbending and bending forces acting on the strip. Strip thickness is the value (e). 


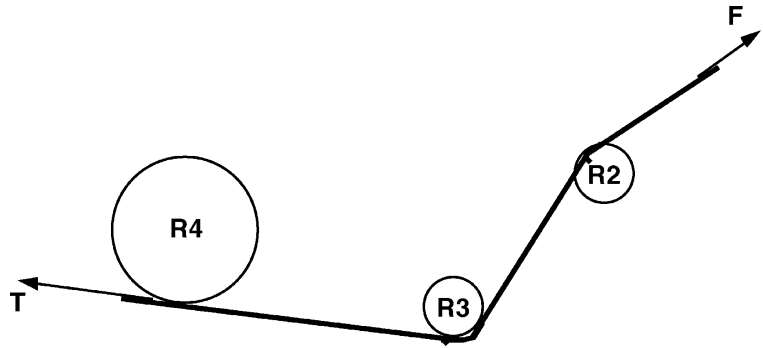

Fig. A.2. Diagram to model the strip traction forces with several cylinders.

\section{A.2. Model of the forces acting on the strip when it} slides around several rolls or cylinders

The general equation given the force action with several cylinders is detailed in Fig. A.2 and Eq. (A.1)

$F=T-\sum_{i=2}^{4} \frac{2 l K}{(n+1)(n+2) R_{i}^{(n+1)}}\left(\frac{e}{2}\right)^{(n+2)}\left(2-3 a_{\mathrm{ci}}\right)$

where $F$ is restrained force $(\mathrm{N}), T$ is tensile force $(\mathrm{N}), l$ is strip width ( $\mathrm{mm}), n$ is strip hardening coefficient, $K$ is consistancy $(\mathrm{MPa}), R_{\mathrm{i}}$ is cylinder radii $(\mathrm{mm}), e$ is strip thickness $(\mathrm{mm}), a_{\mathrm{ci}}$ is coefficient of the dissipated energy by plastic deformation of the strip bending. This value is estimated with the fractional part of the contact surface of strip bending $\left(a_{\mathrm{mp}}\right)$ and unbending $\left(a_{\mathrm{md}}\right)$ on the die radius. This value is assessed with the calculation of contact surface fraction due to bending.

The specific equations given the force action with a blankholder and a portion of a die radius (DDPS) are detailed in Fig. A.3 and Eqs. (A.2) and (A.3).

$H=2 f_{\mathrm{BH}} P+F_{\mathrm{t}}$

$T^{\prime}-F_{\mathrm{u}}=\left(H+F_{\mathrm{b}}\right) \mathrm{e}^{f_{\mathrm{m}}\left(R_{\mathrm{m}} / R_{\mathrm{m}}+e / 2\right)^{\theta}}$

where $f_{\mathrm{BH}}$ is friction coefficient between the strip and the flat blankholder, $H$ is restrained force $(\mathrm{N}), P$ is blankholder $\operatorname{normal} \operatorname{load}(\mathrm{N}), T^{\prime}$ is tensile force $(\mathrm{N}), F_{\mathrm{t}}$ is strip tensile force induced by the decurler and the unrolling engine $(\mathrm{N}), F_{\mathrm{b}}$ is

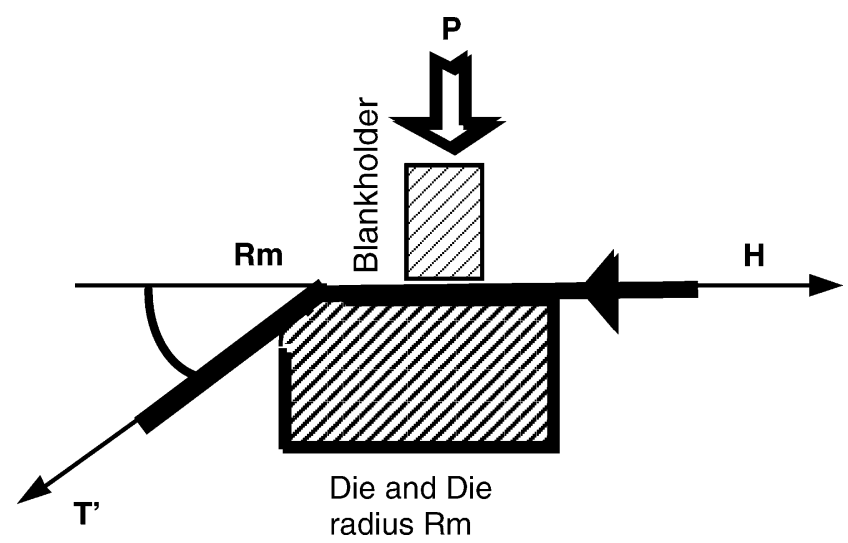

Fig. A.3. Model of blankholder friction coefficient on our DDPS.
Table A.1

Characteristics of the engines and definitions of the used electrical currents

\begin{tabular}{|c|c|c|}
\hline$\eta_{\mathrm{m}}$ & Engine output & 0.82 \\
\hline$\eta_{\mathrm{ener}}$ & Gear motor output & 0.95 \\
\hline$K_{\mathrm{r}}$ & Gear motor reduction coefficient & 36 \\
\hline $\cos (\phi)$ & Power coefficient & 0.84 \\
\hline$U(\mathrm{~V})$ & Engine voltage & 380 \\
\hline$I(\mathrm{~A})$ & $\begin{array}{l}\text { Engine current during friction tests on the } \\
\text { DDPS (tests conditions) }\end{array}$ & $\begin{array}{l}\text { Experiment } \\
\text { value }\end{array}$ \\
\hline$I_{\text {empty }}(\mathrm{A})$ & $\begin{array}{l}\text { Engine current measured without the } \\
\text { blankholder pressure and friction }\end{array}$ & $\begin{array}{l}\text { Experiment } \\
\text { value }\end{array}$ \\
\hline$I_{\text {decurler }}(\mathrm{A})$ & $\begin{array}{l}\text { Engine current measured with the decurler } \\
\text { effect but without the blankholder pressure }\end{array}$ & $\begin{array}{l}\text { Experiment } \\
\text { value }\end{array}$ \\
\hline$I_{0}(\mathrm{~A})$ & $\begin{array}{l}\text { Engine current measured without the } \\
\text { blankholder pressure, without die radius } \\
\text { friction and without decurler effect }\end{array}$ & $\begin{array}{l}\text { Experiment } \\
\text { value }\end{array}$ \\
\hline$I_{\text {load }}(\mathrm{A})$ & $\begin{array}{l}\text { Engine current measured with the blankholder } \\
\text { pressure and the strip exit angle }=0^{\circ} \text {, value } \\
\text { used to measure } \mu_{\mathrm{BH}}\end{array}$ & $\begin{array}{l}\text { Experiment } \\
\text { value }\end{array}$ \\
\hline$V(\mathrm{~mm} / \mathrm{s})$ & Strip linear speed & 50 \\
\hline
\end{tabular}

bending forces acting on the strip $(\mathrm{N}), F_{\mathrm{u}}$ is unbending forces acting on the strip $(\mathrm{N})$.

\section{A.3. Model of the die radius friction coefficient on our $D D P S$}

To determine the value $F_{\mathrm{t}}$, and $T^{\prime}$, the engines characteristics are necessary (evolution of the engine electrical current during strip sliding). They are detailed in Table A.1. The main effects acting on the engine current are the decurler effect, the blankholder pressure, the blankholder friction, the die radius friction, the strip exit angle, the unrolling and rolling up effects and the coil diameter.with

$$
\begin{aligned}
T^{\prime}-F_{\mathrm{u}}= & \frac{\sqrt{3} U \cos (\phi) \eta_{\mathrm{m}} \eta_{\mathrm{ener}} K_{\mathrm{r}}\left(I-I_{\mathrm{empty}}\right)}{v} \\
& +F_{\mathrm{t}}-\frac{2 l K}{(n+1)(n+2) R^{(n+2)}} \\
& \times\left(\frac{e}{2}\right)^{(n+2)}\left(2-3 a_{\mathrm{mp}}\right) a_{\mathrm{md}} \\
H+F_{\mathrm{b}}= & \frac{\sqrt{3} U \cos (\phi) \eta_{\mathrm{m}} \eta_{\mathrm{ener}} K_{\mathrm{r}}\left(I_{\text {load }}-I_{\mathrm{empty}}\right)}{v} \\
& +F_{\mathrm{t}}+\frac{2 l K}{(n+1)(n+2) R^{(n+2)}} \\
& \times\left(\frac{e}{2}\right)^{(n+2)}\left(2-3 a_{\mathrm{mp}}\right) a_{\mathrm{mp}} \\
F_{\mathrm{t}}=\frac{\sqrt{3} U}{\cos (\phi) \eta_{\mathrm{m}} \eta_{\mathrm{ener}} K_{\mathrm{r}}\left(I_{\mathrm{decurler}}-I_{0}\right)} & v
\end{aligned}
$$

All the forces are detailed to calculate the friction coefficient (Eq. (1)) of the die radius on our DDPS.

\section{References}

[1] F. Ronde-Oustau, Conception et mise au point d'une gamme d'emboutissage, Techniques de l'Ingénieur.

[2] V.Samper-Mangin, Etude théorique et expérimentale du frottement et des forces de retenue en emboutissage des tôles d'acier nues et galvanisées, Ph.D. thesis, ENSMP, France, 1993. 
[3] E. Felder, Tribologie de l'emboutissage, Matériaux et Techniques 1-3 (1993) 49-72.

[4] H.Y. Kim, B.C. Hwang, W.B. Bae, An experimental study on forming characteristics of pre-coated sheet metals, J. Mater. Process. Technol. 120 (2002) 290-295.

[5] G.J. Coubrough, M.J. Alinger, C.J. Van Tyne, Angle contact between sheet and die during stretch-bend deformation as determined on the bending-under-tension friction test system, J. Mater. Process. Technol. 130-131 (2002) 69-75.

[6] M. Ericksen, The influence of die geometry on tool wear in deepdrawing, Wear 207 (1997) 10-15.

[7] D. Attaf, Etude et analyse de la dégradation des rayons de matrice en emboutissage, Ph.D. thesis, ENSMP, 2003.

[8] D. Attaf, L. Penazzi, C. Boher, C. Levaillant, Mechanical study of a sheet metal forming dies wear, in: Proceedings of the Sixth International Tooling Conference, Karlstad University, 10-13 September 2002.

[9] E. Van Der Heide, Lubricant failure in sheet metal forming processes, Ph.D. thesis, University of Twente, 2002.

[10] M. De Rooij, Tribological aspects of unlubricated deepdrawing porocesses, Ph.D. thesis, University of Twente, 1998.
[11] M.R. Jensen, F.F. Damborg, K.B. Nielsen, J. Danckert, Applying the finite element model for determination of tool wear in conventionnal deep-drawing, J. Mater. Process. Technol. 83 (1998) 98-105.

[12] J. Mortesen, J. Dirks, P. Christensen, A combined physical and numerical simulation of tool performance in conventionnal deepdrawing operations, in: Proceedings of the IDDRG Congress, 1994, pp. 233-241.

[13] A.K. Ghosh, A method for determining the coefficient of friction in punch streching of sheet metals, Int. J. Mech. Sci. 10 (1977) 457-470.

[14] P. Terreaux, Emboutissage: Simulation du frottement de la tôle sur l'arrondi de la matrice", Matériaux et Techniques 3-4 (1995) 1521.

[15] N.P. Suh, The delamination theory of wear, Wear 44 (1977) 1-16.

[16] D.A. Rigney, L.H. Chen, G.S. Naylor, Wear process in sliding systems, Wear 100 (1984) 195-219.

[17] D.A. Rigney, Comments on the sliding wear of metals, Tribol. Int. 30 (5) (1997) 361-367.

[18] A. Kapoor, Wear by plastic ratchetting, Wear 212 (1997) 119-130.

[19] S.K.R. Chowdhury, H.M. Pollock, Adhesion between metal surfaces: the effect of surface roughness, Wear 66 (1981) 307-321. 